OPEN ACCESS

Edited by:

Junhua Peng,

Center for Life Sci\&Tech of China National Seed Group Co. Ltd, China

Reviewed by:

Xiaoli Jin,

Zhejiang University, China

Kaijun Zhao,

Institute of Crop Sciences (CAAS),

China

${ }^{*}$ Correspondence:

Xujing Wang

xujingwang0514@126.com

Zhixing Wang

wangzx20150618@sina.com

Specialty section:

This article was submitted to

Plant Biotechnology,

a section of the journal

Frontiers in Plant Science

Received: 09 February 2017

Accepted: 11 May 2017

Published: 30 May 2017

Citation:

Dong $Y$, Jin $X$, Tang $Q$, Zhang $X$

Yang J, Liu X, Cai J, Zhang $X$,

Wang $X$ and Wang $Z$ (2017)

Development and Event-specific

Detection of Transgenic

Glyphosate-resistant Rice Expressing

the G2-EPSPS Gene.

Front. Plant Sci. 8:885.

doi: 10.3389/fpls.2017.00885

\section{Development and Event-specific Detection of Transgenic Glyphosate-resistant Rice Expressing the G2-EPSPS Gene}

\author{
Yufeng Dong', Xi Jin'2, Qiaoling Tang', Xin Zhang', Jiangtao Yang ${ }^{1}$, Xiaojing Liu', \\ Junfeng Cai ${ }^{1}$, Xiaobing Zhang ${ }^{3}$, Xujing Wang ${ }^{1 *}$ and Zhixing Wang ${ }^{1 *}$
}

${ }^{1}$ Biotechnology Research Institute, Chinese Academy of Agricultural Sciences, Beijing, China, ${ }^{2}$ Department of Biochemistry, Baoding University, Baoding, China, ${ }^{3}$ Biology Institute, Hebei Academy of Sciences, Shijiazhuang, China

Glyphosate is a widely used herbicide, due to its broad spectrum, low cost, low toxicity, high efficiency, and non-selective characteristics. Rice farmers rarely use glyphosate as a herbicide, because the crop is sensitive to this chemical. The development of transgenic glyphosate-tolerant rice could greatly improve the economics of rice production. Here, we transformed the Pseudomonas fluorescens G2 5-enolpyruvyl shikimate-3-phosphate synthase (EPSPS) gene G2-EPSPS, which conferred tolerance to glyphosate herbicide into a widely used japonica rice cultivar, Zhonghua 11 (ZH11), to develop two highly glyphosate-tolerant transgenic rice lines, G2-6 and G2-7, with one exogenous gene integration. Seed germination tests and glyphosate-tolerance assays of plants grown in a greenhouse showed that the two transgenic lines could greatly improve glyphosate-tolerance compared with the wild-type; The glyphosatetolerance field test indicated that both transgenic lines could grow at concentrations of 20,000 ppm glyphosate, which is more than 20-times the recommended concentration in the field. Isolation of the flanking sequence of transgenic rice G2-6 indicated that the 5 -terminal of T-DNA was inserted into chromosome 8 of the rice genome. An eventspecific PCR test system was established and the limit of detection of the primers reached five copies. Overall, the G2-EPSPS gene significantly improved glyphosatetolerance in transgenic rice; furthermore, it is a useful candidate gene for the future development of commercial transgenic rice.

Keywords: G2-EPSPS, 5-enolpyruvylshikimate-3-phosphate, glyphosate, event-specific PCR, rice

\section{INTRODUCTION}

Rice is one of the four most commonly farmed arable crops (Ray et al., 2013) with about $90 \%$ of world production being grown and consumed in Asia (Singh et al., 2016). However, increased rice production is hampered by factors such as decreasing availability of arable land, lack of labor, and water scarcity (Nguyen and Ferrero, 2006). To meet these challenges, there has been a shift from puddled transplanted rice (PTR) to dry direct-seeded rice (DSR) (Farooq et al., 2011). The major challenge for DSR is weed management. Traditional methods of weed control consist predominantly of pulling by hand, or hoeing. In contrast, use of herbicides is more efficient, economical, and labor-saving (Singh et al., 2016). 
Glyphosate is a non-selective herbicide first produced by Monsanto in 1970 . Its mode of action is to disrupt aromatic amino acid synthesis by inhibiting the enzyme 5-enolpyruvylshikimate-3-phosphate synthase (EPSPS) of the shikimate pathway, thereby controlling the vast majority of weeds. Its qualities of being site-specific, having low toxicity against humans and in the environment, being low-cost, and being broad-spectrum, make glyphosate one of the world's most commonly used herbicides (Williams et al., 2000; Duke and Powles, 2008). Despite these qualities, glyphosate is rarely used in paddy cultivation because it is harmful to rice. Therefore, the development of glyphosate-tolerant rice cultivars will benefit farmers by reducing labor, water, and energy consumption, which in turn will improve the economics of rice production.

There are two ways to obtain glyphosate-resistant crops: introducing a mutant allele encoding a less-sensitive bacterial enzyme (Stalker et al., 1985), or the overproduction of EPSPS enzyme (Shah et al., 1986; Goldsbrough et al., 1990). In the development of glyphosate-resistant rice, studies on the following genes have taken place: G6 gene (Zhao et al., 2011), MdEPSPS mutant (Tian et al., 2013), OsEPSPS mutant (Chandrasekhar et al., 2014), CP4-EPSPS (Chhapekar et al., 2015), VvEPSPS mutant (Tian et al., 2015), AroAJ.sp (Yi et al., 2016), and I. variabilis-EPSPS* (Cui et al., 2016). The ability of each of these genes to enhance the resistance of rice to glyphosate is not the same. In fact, among these genes, only the CP4-EPSPS gene has been widely used for developing commercial glyphosate-tolerant crops; furthermore, the mepsps and 2 mepsps genes were only used on a few types of GM plants ${ }^{1}$. The single source of the EPSPS gene is probably the cause of the reduction in herbicide tolerance; the latter has become the main concern of those involved in field management programs (Tian et al., 2015). For these reasons, exploration of the application of the glyphosate-tolerance gene to a variety of crops has great agricultural significance.

The G2-EPSPS gene (GenBank Accession No.: EF155478) encoding a highly glyphosate-resistant EPSPS protein was identified from Pseudomonas fluorescens strain G2, which was isolated from a storage area with a history of glyphosate pollution (Zhu et al., 2003). Dun et al. (2007) transferred the G2-EPSPS gene into tobacco and the transgenic tobacco plants were capable of achieving normal growth at $1 \%$ glyphosate. When the G2-EPSPS was transferred into cotton by Zhang et al. (2016), the herbicide-resistant cotton cultivar BG2-7 was created, in which glyphosate resistance reached $8000 \mathrm{ppm}$. Guo et al. (2015) co-expressed the G2-EPSPS and GAT genes in soybean, and no typical symptoms of glyphosate poisoning were observed in the transgenic soybean at 900-3600 g a.e. ha ${ }^{-1}$. Liu et al. (2015) transferred the same gene into maize; when the transgenic maize was subsequently sprayed with $4 \mathrm{~g} \mathrm{~L}^{-1}$ glyphosate at a dose of $2.46 \mathrm{~kg} \mathrm{ha}^{-1}$, the G2-EPSPS conferred good resistance even after 3 days. The above results therefore indicate that G2-EPSPS is a good candidate gene for improving glyphosate resistance in a variety crops. However, its effects in rice have not yet been reported; whether it can confer a comparable degree of glyphosate resistance in this crop is unknown.

${ }^{1}$ http://www.isaaa.org/gmapprovaldatabase/default.asp
In the current study, the G2-EPSPS gene was transferred into rice plants to produce transgenic rice with good resistance to glyphosate. Furthermore, the effects of different concentrations of glyphosate on the growth of transgenic rice were studied. The insertion site of T-DNA was determined by cloning the left flanking sequence of G2-6 transgenic rice. An event-specific PCR detection method was developed, using specifically designed primers, to detect line G2-6 and to establish the lower limit of detection.

\section{MATERIALS AND METHODS}

\section{Construction of Plant Transformation Vector and Rice Transformation}

The Chrysanthemum $x$ morifolium ribulose-1,5-bisphosphate carboxylase small subunit chloroplast signal peptide gene CTS was amplified from Impactvector 1.4 by PCR with primers CTS1/CTS-2, and the G2-EPSPS gene was cloned from Pseudomonas fluorescens by PCR with primers G2-1/G2-2. The CTS::G2EPSPS fusion gene was amplified by overlap PCR, using primers containing a $B a m \mathrm{H}$ I restriction site at the $5^{\prime}$-end of forward primer (BamH I-CTS-1: GGATCCggatcctatggcctcgatctcttcc) and a Sac I restriction site at the $5^{\prime}$-end of reverse primer (Sac I-G22: GAGCTCgagctctcagtcgtttaggtgaacg), respectively. The PCR conditions were five cycles of $95^{\circ} \mathrm{C}$ for $25 \mathrm{~s}, 65^{\circ} \mathrm{C}$ for $25 \mathrm{~s}$, and then $72^{\circ} \mathrm{C}$ for $70 \mathrm{~s}$ with no primers. Subsequently, primers were added into the PCR tube, and the cycle was run at $95^{\circ} \mathrm{C}$ for $5 \mathrm{~min}$, followed by 29 cycles at $95^{\circ} \mathrm{C}$ for $25 \mathrm{~s}, 57^{\circ} \mathrm{C}$ for $25 \mathrm{~s}$, and $72^{\circ} \mathrm{C}$ for $70 \mathrm{~min}$; and finally $72^{\circ} \mathrm{C}$ for $5 \mathrm{~min}$. The UBI promoter from pHAC25 was sub-cloned into pBI121 with Hind III and $B a m H$ I restriction sites to generate the pUBI121 vector. The fusion gene CTS::G2-EPSPS was inserted into the pUBI121 vector by BamH I and Sac I to generate the pUBI121::CTS::G2EPSPS vector. Subsequently, the new vector was digested by Hind III and EcoR I and cloned into the multiple cloning site of pCAMBIA1301 to generate the vector 13UG2 (Figure 1A). The vector was introduced into Agrobacterium tumefaciens EHA105. Transformation of the Japonica cultivar ZH11 was performed based on the method reported by Hiei et al. (1994).

\section{PCR Analysis of Transgenic Rice}

Rice genomic DNA was isolated from hygromycin resistance rice leaves using the modified CTAB method (Porebski et al., 1997) and amplified with the primers G2-F and G2-R1 (Supplementary Table S1). PCR was carried out with 50 ng of rice genomic DNA, $10 \mu \mathrm{l}$ of $2 \times$ PCR mix $(2 \times$ EasyTaq PCR SuperMix, Transgene, Beijing, China), and $0.5 \mu \mathrm{l}$ each of G2-F $(10 \mu \mathrm{M})$ and G2-R1 $(10 \mu \mathrm{M})$. The PCR conditions were $95^{\circ} \mathrm{C}$ for $8 \mathrm{~min}$, followed by 32 cycles of $95^{\circ} \mathrm{C}$ for $25 \mathrm{~s}, 53^{\circ} \mathrm{C}$ for $40 \mathrm{~s}$, and $72^{\circ} \mathrm{C}$ for $1 \mathrm{~min}$; and finally, $72^{\circ} \mathrm{C}$ for $5 \mathrm{~min}$.

\section{Western Blot Analysis}

Total protein was extracted from $0.1 \mathrm{~g}$ of transgenic rice leaves using a Plant Protein Extraction Kit (CWBIO, CW0885, Beijing, China), and the amount of protein was calculated using the 


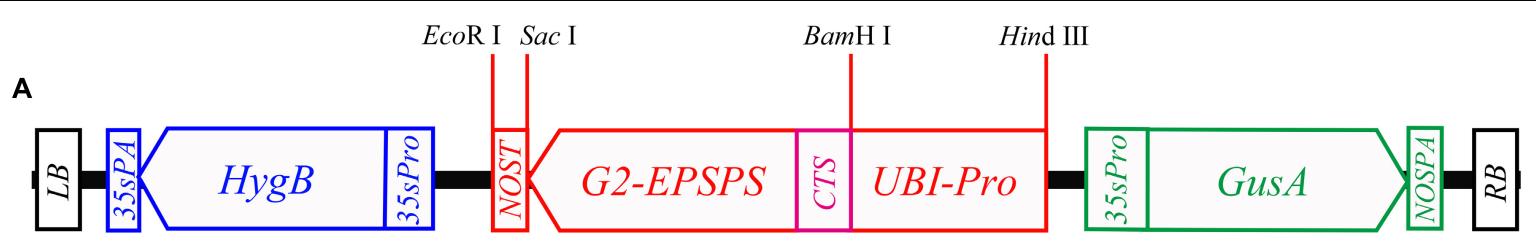

B
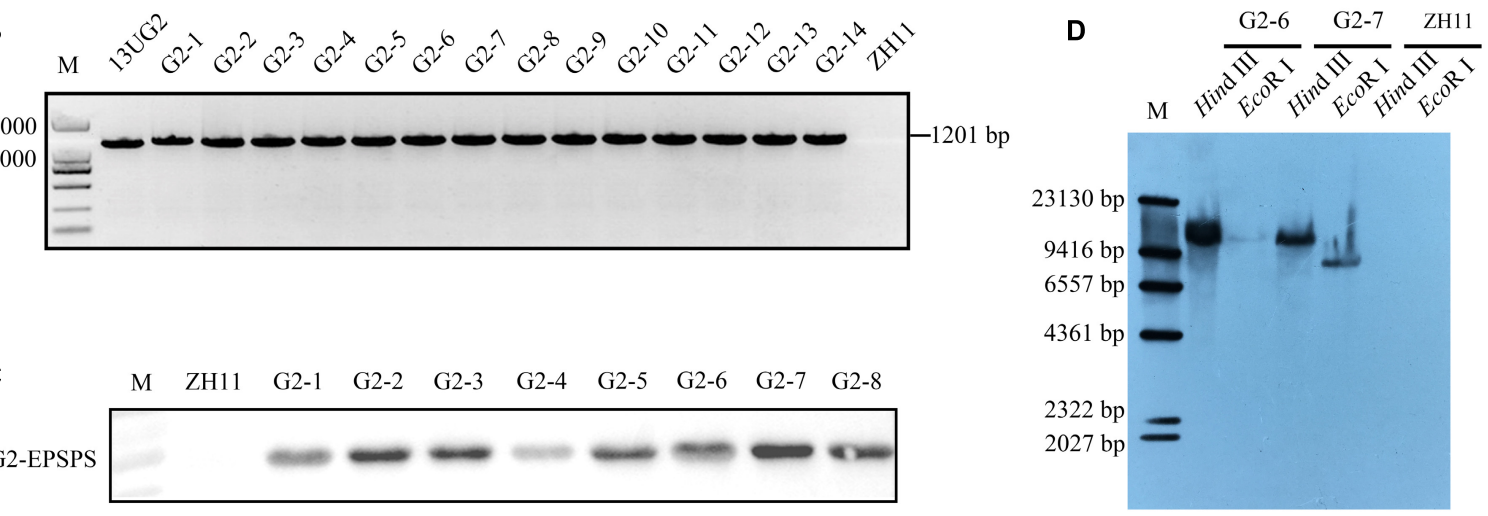

C $\begin{array}{llllllllll}\text { M } & \text { ZH11 } & \text { G2-1 } & \text { G2-2 } & \text { G2-3 } & \text { G2-4 } & \text { G2-5 } & \text { G2-6 } & \text { G2-7 } & \text { G2-8 }\end{array}$

G2-EPSPS

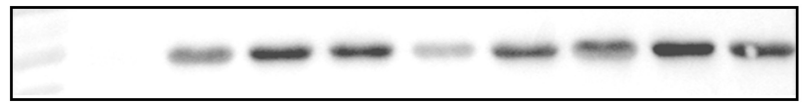

FIGURE 1 | Transformation and detection of transgenic rice. (A) Diagrams of the plasmid constructs UB1::CTS::G2-EPSPS, containing the CTS::G2-EPSPS coding region with a nos terminator under control of the UBI promoter. (B) The transgenic-line-specific PCR was implemented using G2-EPSPS gene-specific primers. The vector 13UG2 was used as the positive control (lane 13UG2), and ZH11 DNA was used as the negative control (lane ZH11). (C) Expression analysis of the G2-EPSPS protein in the shoot of ZH11 (designated as negative control) and eight UB1::CTS:: G2-EPSPS T0 transgenic lines (G2-1, G2-2, G2-3, G2-4, G2-5, G2-6, G2-7, G2-8). (D) Transgenic rice genome DNA was digested with restriction endonuclease Hindlll and EcoRI. The DIG-labeled G2-EPSPS gene probe was used to detect T-DNA copy number in transgenic lines.

bicinchoninic acid (BCA) method. About $10 \mu \mathrm{g}$ of protein was denatured at $95^{\circ} \mathrm{C}$ for $8 \mathrm{~min}$, and then resolved by SDS-PAGE on $12 \%$ gels; proteins were then wet-blotted onto a nitrocellulose filter membrane. The G2-EPSPS protein was detected using the primary monoclonal antibody, anti-G2-EPSPS $(3 \mathrm{mg} / \mathrm{ml}$, 1:2000 dilution), which was obtained from immune mice using G2-EPSPS protein purified from the prokaryotic expression system. Horseradish peroxidase- (HRP)-labeled goat anti-mouse antibodies were used as the secondary antibody diluted at a ratio of 1:5000, and enhanced chemiluminescence (ECL) was used to detect the blot.

\section{Southern Blot Analysis}

Aliquots of $40 \mu \mathrm{g}$ purified DNA were digested with Hind III and EcoR I, respectively. The digested DNA fragments were separated on a $0.8 \%$ agarose gel and then blotted onto Hybond ${ }^{\mathrm{TM}}-\mathrm{N}^{+}$ nylon membrane (GE Healthcare UK Limited). The probe was amplified using primers G2-F/G2-R2 (Supplementary Table S1), and labeled with DIG (PCR DIG Probe Synthesis Kit, Roche, Germany). The blot was washed and detected according to the product instructions (DIG High Prime DNA Labeling and Detection Starter KitII , Roche, Germany).

\section{Plant Material and Growth Conditions}

For glyphosate-tolerance studies, seeds from each of the nontransgenic control $\mathrm{ZH} 11$ and homozygous transgenic plants $\left(\mathrm{T}_{3}\right.$ generation) were germinated in ultrapure water containing different concentrations of glyphosate at $37^{\circ} \mathrm{C}$ for 1 day in the dark. To test seed germination in ZH11 and transgenic lines, 40 seeds per dish were grown in 0,50 , and $100 \mathrm{ppm}$ concentrations of glyphosate for 6 days. The glyphosate used in the report was Roundup, which contains $41 \%$ isopropyl amine salt of glyphosate (Monsanto, Malaysia), and 1000 ppm glyphosate, equivalent to $0.25 \%(\mathrm{v} / \mathrm{v})$ Roundup.

For experimental analyses, seeds from the non-transgenic control ZH11 and transgenic lines $\left(\mathrm{T}_{3}\right.$ generation) were germinated in ultrapure water at $37^{\circ} \mathrm{C}$ for 1 day in the dark, and then transferred into soil in the greenhouse under controlled conditions. About 30 seedlings of $\mathrm{ZH} 11$ per pot were grown for 4 weeks, and then sprayed with 0,1000, 2000, or 3000 ppm of glyphosate to test for lethal concentrations. The two homozygous transgenic lines were each sprayed with 0, 3000, 5000, 8000, $10,000,12,000,15,000$, or 20,000 ppm of glyphosate at the tillering stage. Twelve days later, all treated plants were photographed and shoot height was measured.

For the glyphosate-tolerance assay, seeds of $\mathrm{ZH} 11$ and transgenic lines ( $\mathrm{T}_{4}$ generation) were transferred to $1 / 2$ Yoshida hydroponic culture with $1 \mathrm{mM} \mathrm{NH} \mathrm{mHO}_{3}$ (pH 5.5) containing different concentrations of glyphosate for 10 days, and the nutrient solution was changed every day. ZH11 was grown in 0 , $0.01,0.1,0.2,0.5,1,4$, and 16 ppm glyphosate; transgenic plants were grown in $0,5,10,25,50,100,200,800$ ppm glyphosate for 10 days. The seedlings were kept in a growth chamber [28 ${ }^{\circ} \mathrm{C}$; 14-h/10-h light/dark photoperiod; $90 \%$ humidity; photon 
flux density, $500 \mu \mathrm{mol} / \mathrm{m}^{2} / \mathrm{s}$ photosynthetically active radiation (PAR)]. After 10 days, all the plants were collected. Plant height data at each glyphosate concentration were expressed as relative height, by comparing the mean height of each transgenic line at each concentration with its mean height at 0 ppm glyphosate. The relative heights at different concentrations could be fitted to a sigmoidal logistic model to produce dose-response curves (Seefeldt et al., 1995; Cui et al., 2016).

\section{RNA Isolation and Quantitative RT-PCR Analysis}

Total RNA was extracted from control and transgenic plant shoot tissues using RNAiso Plus (Takara Biotechnology, Dalian, China). Approximately $1.5 \mu \mathrm{g}$ of total RNA was used to synthesize firststrand cDNA using a PrimeScript ${ }^{\mathrm{TM}}$ RT reagent Kit with gDNA Eraser (Takara). In the transgenic plant expression analyses, transcript levels were normalized to those of the OsUBQ5 gene, and G2-EPSPS gene expression level was detected by the primers G2-151F/G2-151R (Supplementary Table S1). Real-time PCR was carried out in 7500 Real-Time PCR System (Applied Biosystems, United States) in $20 \mu \mathrm{l}$ reaction mixtures containing $2 \mu \mathrm{l}$ cDNA sample (1:20 dilution), $0.4 \mu \mathrm{l}$ forward primers $(10 \mu \mathrm{m}), 0.4 \mu \mathrm{l}$ reverse primers $(10 \mu \mathrm{m}), 0.4 \mu \mathrm{l}$ Dye II and $10 \mu \mathrm{l}$ SYBR Green Real-time PCR Mix (Takara Biotechnology, Dalian, China), the PCR conduction was at $95^{\circ} \mathrm{C}$ for $15 \mathrm{~s}$, followed by 40 cycles of $95^{\circ} \mathrm{C}$ for $5 \mathrm{~s}$ and $60^{\circ} \mathrm{C}$ for $34 \mathrm{~s}$.

\section{Isolation of the Flanking Sequence of T-DNA}

The GenomeWalker ${ }^{\mathrm{TM}}$ Universal Kit (Clontech, Takara) was used to isolate the flanking sequence of T-DNA; $25 \mu \mathrm{g}$ of transgenic rice genomic DNA was digested with restriction endonucleases DraI, EcoR V, PvuII, and StuI, respectively, and the adaptor supplied in the kit was added. The specific primer GPS1/2 was designed and combined with the left boundary of the T-DNA. PCR was conducted according to the kit protocol. The sequence was analyzed using BLAST software in the NCBI database to search for the integration feature of T-DNA on the rice genome using the Rice Genome Annotation Project database ${ }^{2}$.

\section{Establishment of Event-Specific PCR and Genomic DNA Detection Limit for Transgenic Plants}

For integration event-specific PCR detection analysis, the multiplex PCR method was used. The event-specific primers $\mathrm{G}_{2}-\mathrm{OsF} / \mathrm{G}_{2}-\mathrm{GR}$ were designed according to the $5^{\prime}$-flanking sequence of the T-DNA of G2-6 transgenic rice and the sequence near the left-border of 13UG2. Additionally, OsSPS (sucrosephosphate synthase 1, LOC_Os01g69030) specific primers SPSF/SPSR were designed, as a positive control in the multiplex amplification system (Supplementary Table S1). Multiplex PCR was conducted using genomic DNA isolated from transgenic rice with different integration events as the template. The PCR conditions were $95^{\circ} \mathrm{C}$ for $8 \mathrm{~min}$, followed by 32 cycles at $95^{\circ} \mathrm{C}$ for

${ }^{2}$ https://blast.ncbi.nlm.nih.gov/Blast.cgi
$25 \mathrm{~s}, 54^{\circ} \mathrm{C}$ for $25 \mathrm{~s}$, and $72^{\circ} \mathrm{C}$ for $30 \mathrm{~s}$; and then extension at $72^{\circ} \mathrm{C}$ for $5 \mathrm{~min}$.

To determine the detection limit for transgenic plants, the concentration of template DNA isolated from G2-6 was measured and diluted to $5,10,20,40,80,160$, and 320 copies, respectively. Then, to identify the detection limit using the integration-eventspecific PCR system, a negative control was performed without using the DNA template.

\section{RESULTS}

\section{Production and Identification of Transgenic Rice}

A total of 46 independent transgenic plants were obtained. Rice genomic DNA was isolated from $\mathrm{T}_{0}$ generation transgenic plants, and PCR amplification was performed with G2-EPSPS specific primers G2-F/G2-R1. A 1201 bp fragment was produced in the transgenic rice, whereas PCR products could not be amplified in $\mathrm{ZH} 11$, showing that the target gene was successfully integrated (Figure 1B). To determine G2-EPSPS protein expression in transgenic rice, proteins were extracted from PCR-positive transgenic rice leaves, and all the selected transgenic lines had G2EPSPS protein expression; here only eight results were listed, as shown in Figure 1C. Southern blotting was performed with the $\mathrm{T}_{0}$-generation plant DNA. Results showed that G2-6 and G2-7 contained a single copy of the G2-EPSPS gene (Figure 1D). The G2-EPSPS gene had similar expression levels in leaves of both G2-6 and G2-7 (Supplementary Figure S1).

\section{Glyphosate-Tolerance of Germinated Homozygous Transgenic Lines G2-6 and G2-7}

Glyphosate can affect seed germination, and seeds are usually inhibited and bleached under glyphosate stress (Dun et al., 2007). To investigate the agronomic performance of the two transgenic lines, seeds and soil culture seedlings were treated with different concentrations of glyphosate. Seeds from ZH11, G2-6, and G2-7 were germinated in ultrapure water with 0,50 , and 100 ppm glyphosate for 6 days (Figure 2). The results showed that G2-6 and G2-7 could germinate well at $50 \mathrm{ppm}$ and $100 \mathrm{ppm}$ concentration of glyphosate; the radicle also grew normally at 100 ppm glyphosate, whereas ZH11 germination was obviously inhibited at 50 ppm glyphosate, and completely inhibited at 100 ppm glyphosate. These findings indicated that transgenic lines were more tolerant to glyphosate than the non-transgenic variety $\mathrm{ZH} 11$.

\section{Glyphosate-Tolerance of Homozygous Transgenic Lines G2-6 and G2-7 in the Field}

Four-weeks-old seedlings of the control ZH11 were treated with 0, 1000, 2000, and 3000 ppm glyphosate. After 12 days, all treated ZH11 plants were dead, leaving only the 0 ppm glyphosate treatment group alive (Figure 3A). This result indicated that in the field, 1000 ppm glyphosate is a lethal concentration for rice. 


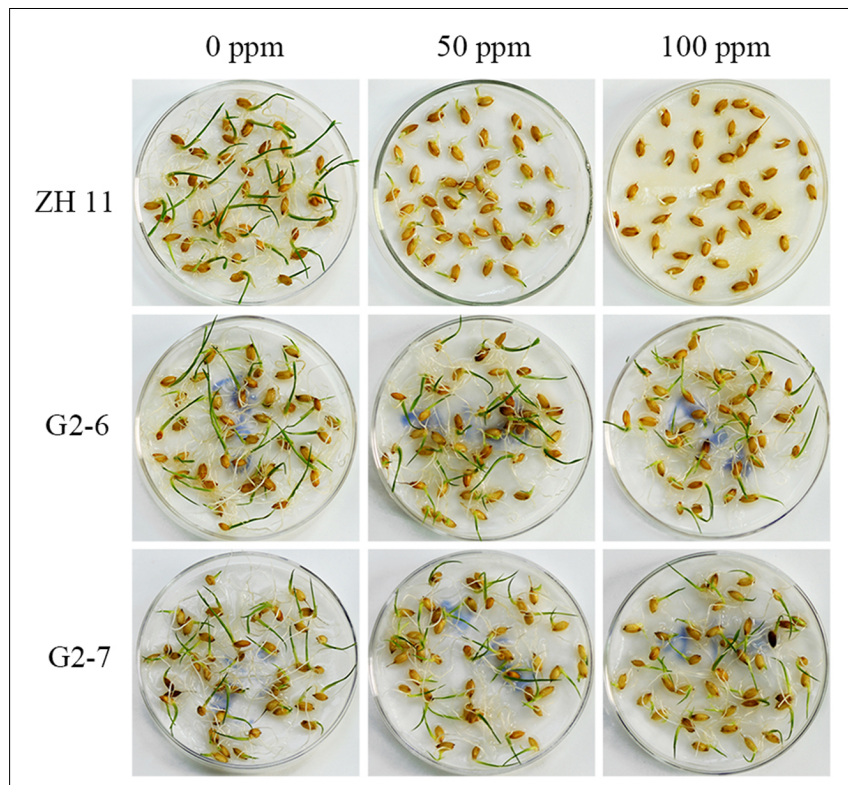

FIGURE 2 | Germination of transgenic plant seeds under different concentrations of glyphosate. Sprouting of homozygous transgenic lines (G2-6, G2-7) on ultrapure water containing 0, 50, or 100 ppm glyphosate for 6 days.

To determine the tolerance of the transgenic cultivars G26 and G2-7 to much higher glyphosate concentrations, they were treated with $0,3000,5000,8000,10,000,12,000,15,000$, or 20,000 ppm glyphosate in the field at the tillering stage. After 12 days, plants under all treatments were fully expanded and green, but the shoot heights were different and were therefore used for statistical analysis of the agronomic performance of transgenic lines (Figures 3B,C). There were significant differences in plant shoot height between homozygous lines and glyphosate dosages (Table 1).

When treated with $3000 \mathrm{ppm}$ or higher glyphosate, shoot heights of both transgenic lines were significantly decreased compared with untreated group, whereas at 8000 , $10,000,12,000,15,000$, and $20,000 \mathrm{ppm}$ of glyphosate, the shoot heights of G2-6 and G2-7 exhibited no significant differences, respectively. Furthermore, shoot height of G2-6 was decreased by $15.3 \%$ when compared with G2-7 in the 20,000 glyphosate treatment group. These results indicated that G2-7 may show better agronomic performance than G2-6, although they exhibited similar expression levels. With further cultivation, the differences of shoot height disappeared at the heading stage; all treatments then progressed to the same height as the untreated group, and produced seeds normally.

\section{Glyphosate-Tolerance of Homozygous Transgenic Lines G2-6 and G2-7 in a Hydroponic System}

There were significant differences in plant shoot height and plant fresh weight between homozygous lines, and with

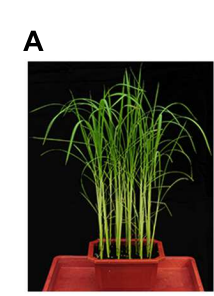

0

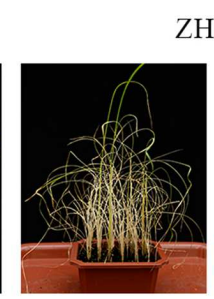

$1000 \mathrm{ppm}$
ZH 11

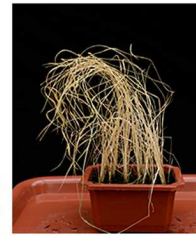

$2000 \mathrm{ppm}$

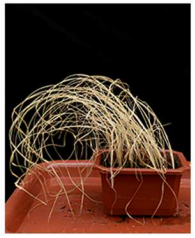

3000 ppm
B

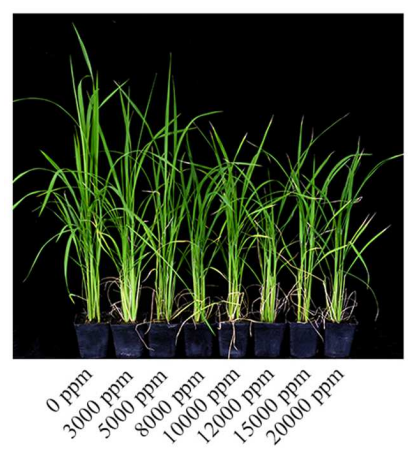

C $\quad$ G2-7

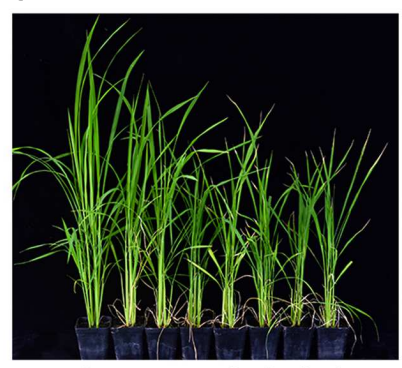

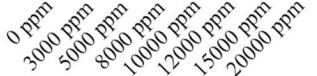

FIGURE 3 | Rice growth phenotype under different concentrations of glyphosate treatment. (A) ZH11 grown in the greenhouse for 4 weeks, and photographed 12 days after treatment with 0, 1000, 2000, or 3000 ppm glyphosate. (B,C) transgenic plants G2-6 and G2-7 grown in the greenhouse at the tillering stage, and photographed 12 days after treatment with 0, 3000, $5000,8000,10,000,12,000,15,000$, or 20,000 ppm glyphosate.

glyphosate dosage. In the hydroponic system, increase in shoot height and plant fresh weight of $\mathrm{ZH} 11$ could be significantly inhibited at $0.2 \mathrm{ppm}$ glyphosate. The ZH11 seedlings were decomposed at 4 ppm glyphosate concentration, and according to the dose response curve, the relative seedling height was not obviously reduced with increasing glyphosate concentration; the results indicated that $\mathrm{ZH} 11$ was completely inhibited by $4 \mathrm{ppm}$ glyphosate (Figure $\mathbf{4 A}$ and Table 2).

For G2-6 and G2-7, at increased treatment concentrations of glyphosate, shoot heights were significantly decreased to differing degrees (Table 3 and Figure 4A). For G2-6, shoot height and plant fresh weight was significantly inhibited at 10 ppm glyphosate, whereas for G2-7 the corresponding inhibitory concentration was 50 ppm. For both G2-6 and G27, shoot height and plant fresh weight could be completely inhibited at $800 \mathrm{ppm}$ glyphosate; at this application rate the seedlings performed similar to ZH11 when treated with $4 \mathrm{ppm}$ glyphosate.

To investigate the glyphosate-tolerance of the transgenic lines, dose-response curves were created using the relative shoot heights of ZH11, G2-6, and G2-7 under different glyphosate concentrations (Figure 4B). The results revealed that the $\mathrm{I}_{50}$ for each line was $0.93,96.4$, and 114.07 ppm, respectively. The glyphosate-tolerance of G2-6 and G2-7 was 104- and 123-times that of $\mathrm{ZH} 11$, respectively. 
TABLE 1 | Agronomic performances of selected transgenic lines under different glyphosate treatments.

\begin{tabular}{lcr}
\hline Homozygous lines & Glyphosate dosage (ppm) & Shoot height (cm) \\
\hline G2-6 & 0 & $79.16 \pm 1.53 a$ \\
& 3000 & $64.96 \pm 1.81 b$ \\
5000 & $59.96 \pm 1.45 b$ \\
8000 & $50.02 \pm 1.64 c$ \\
10,000 & $48.32 \pm 4.62 c$ \\
12,000 & $48.1 \pm 6.36 c$ \\
15,000 & $45.91 \pm 1.31 c$ \\
20,000 & $45.09 \pm 3.83 c$ \\
G2-7 & 0 & $78.56 \pm 1.29 a$ \\
& 3000 & $67.45 \pm 2.09 b$ \\
& 5000 & $64.35 \pm 4.52 b$ \\
8000 & $57.1 \pm 3.06 c$ \\
10,000 & $55.6 \pm 2.98 c$ \\
12,000 & $56.23 \pm 2.98 c$
\end{tabular}

Source of variation

Homozygous lines (HL)

Glyphosate dosage (GD)

$\mathrm{HL} \times \mathrm{GD}$

**

**

ns

The parameters are shown as average values ( \pm standard deviation), which were collected from 40 plants in three replicates for each treatment. Numbers followed by different letters indicate significant differences $(P<0.05)$. ns, not significant $(P>0.05)$. ${ }^{* *}$ Significant at $P<0.01$.

To better understand the glyphosate-tolerance phenotype of the transgenic lines, we further analyzed G2-EPSPS gene expression levels in the shoots of plants under the 0 and $100 \mathrm{ppm}$ glyphosate treatments. For both G2-6 and G2-7, there was no significant difference in G2-EPSPS gene expression level between 0 and 100 ppm glyphosate treatment (Figure 4C).

\section{Establishment of an Event-Specific PCR Detection Method}

To analyze the integrity of transgene insertion in the plant genome, we isolated the left-border flanking sequences of T-DNA from the G2-6 transgenic line. Within the obtained 863 bp sequence, there were 612 bp showing $100 \%$ similarity to the $13 \mathrm{UG} 2$ vector sequence. The $251 \mathrm{bp}$ upstream sequences exhibited $99 \%$ similarity to the sequence of Oryza sativa chromosome 8 from 23685037 to 23685287 . The results indicated that the 5'-terminus of T-DNA was inserted at position 23685287 of the Oryza sativa chromosome 8. Further analysis showed that, in G2-6, the distance of the T-DNA integration sites to the upstream protein coding sequence (CDS) was $14 \mathrm{~kb}$ and to the downstream protein CDS it was $26 \mathrm{~kb}$.

To develop event-specific PCR detection of G2-6 and ensure credibility of the PCR system, an endogenous reference gene OsSPS was selected as the positive control. The specific primers G2-OsF/G2-GR were designed according to the sequence of the rice genome and the left-border region of 13UG2, respectively (Figure 5A). A 554 bp fragment could be amplified from G2-6, whereas no PCR product could be amplified
A
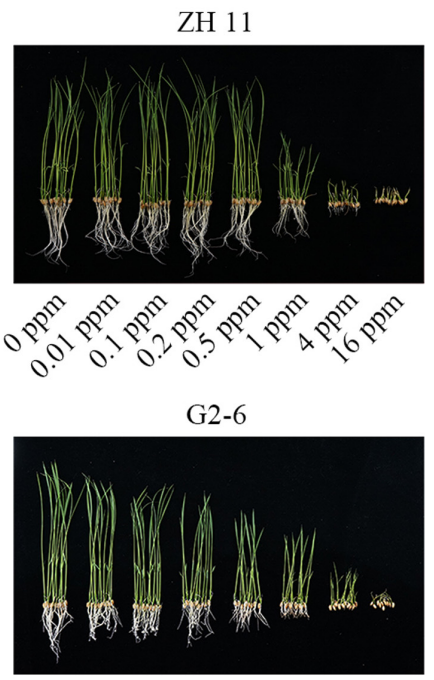

G2-7
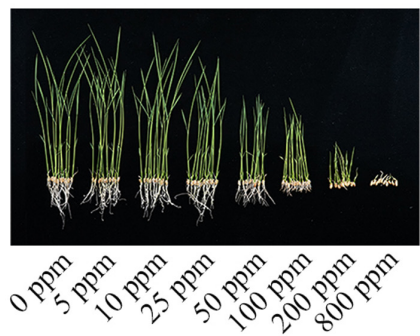

B

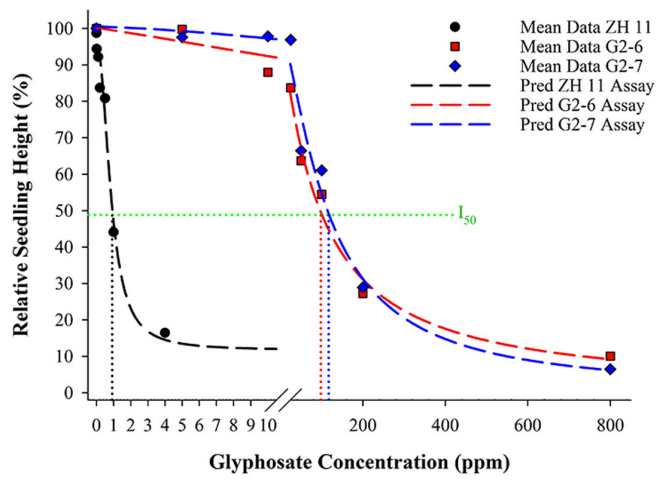

C

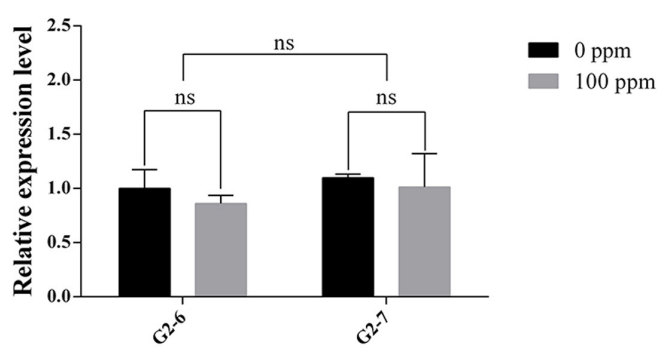

FIGURE 4 | Glyphosate-tolerance assay on hydroponic culture. (A) ZH11, G2-6, and G2-7 seedlings were grown in $1 / 2$ Yoshida hydroponic culture with $1 \mathrm{mM} \mathrm{NH}_{4} \mathrm{NO}_{3}$, containing different concentrations of glyphosate, for 10 days. (B) Dose-response curves for ZH11, G2-6, and G2-7 were drawn

(Continued) 


\section{FIGURE 4 | Continued}

giving the relative plant height in each line. The predicted logistic equations for $\mathrm{ZH} 11, \mathrm{G} 2-6$, and G2-7 are $\mathrm{Y}_{\mathrm{ZH} 11}=11.68+83.58 /\left[1+(\mathrm{X} / 0.86)^{2.18}\right]$

$\left[R^{2}=0.993, I_{50}=0.93\right], Y_{G 2-6}=0.23+99.99 /\left[1+(X / 95.6)^{1.09}\right]\left[R^{2}=0.994\right.$, $\left.I_{50}=96.4\right]$, and $Y_{G 2-7}=0.06+100.5 /\left[1+(X / 113.06)^{1.4}\right]\left[R^{2}=0.989\right.$,

$\left.I_{50}=114.07\right]$. (C) Expression level of G2-EPSPS gene in the shoots of

transgenic lines G2-6 and G2-7 under 0 and 100 ppm glyphosate

concentration. ns, not significant $(P>0.05)$.

from other transgenic lines, ZH11, or the negative control without DNA template. A 151 bp fragment could be amplified from all transgenic lines and the non-transgenic line ZH11, whereas no PCR product could be amplified from the negative control (Supplementary Figure S2). The results confirmed that conventional PCR could identify the specific integration events of G2-6 and could therefore be used successfully for detecting transgenic rice $\mathrm{G} 2-6$.

\section{Sensitivity Testing of the Event-Specific PCR System}

To test the limits of the event-specific PCR system, the DNA template of transgenic rice G2-6 was diluted to 5, 10, 20, 40, 80, 160 , and 320 copies. A weak 554 bp fragment could be amplified from five copies, and with an increase in the template copy number, the brightness increased (Figure 5B). The detection limits were acceptable under the regulatory requirements of China.

\section{DISCUSSION}

Since GM crops have increased in popularity over the last decade, concerns about the safety of GM foods among the public have escalated. For the G2-EPSPS gene, there has been some research regarding the food safety of GM maize. According

TABLE 2 | Hydroponic growth phenotype of non-transgenic lines under different glyphosate treatments.

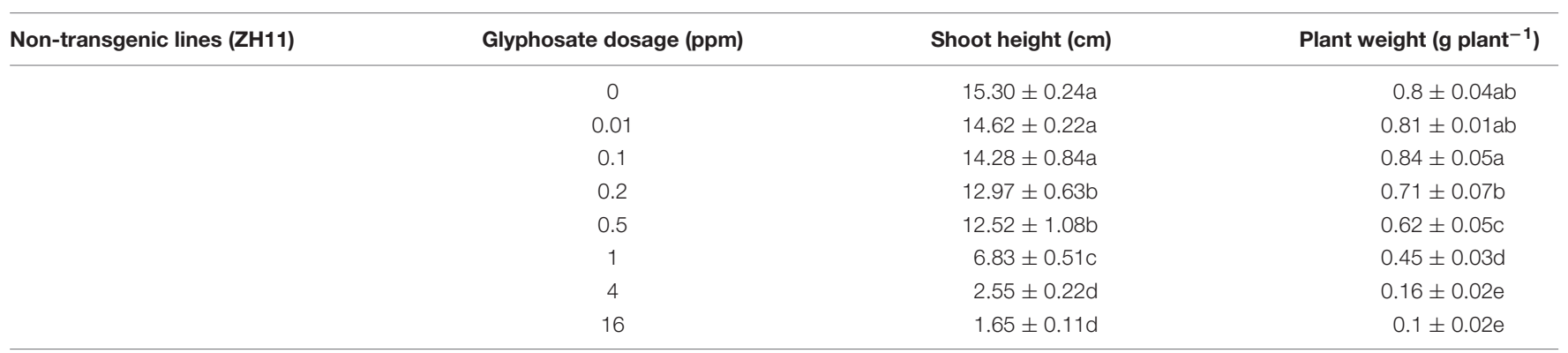

The parameters are shown as average values ( \pm standard deviation) that were collected from 40 plants in three replicates for each treatment. Numbers followed by different letters indicate significant differences $(P<0.05)$.

TABLE 3 | Agronomic performances of the selected transgenic lines under different glyphosate treatments.

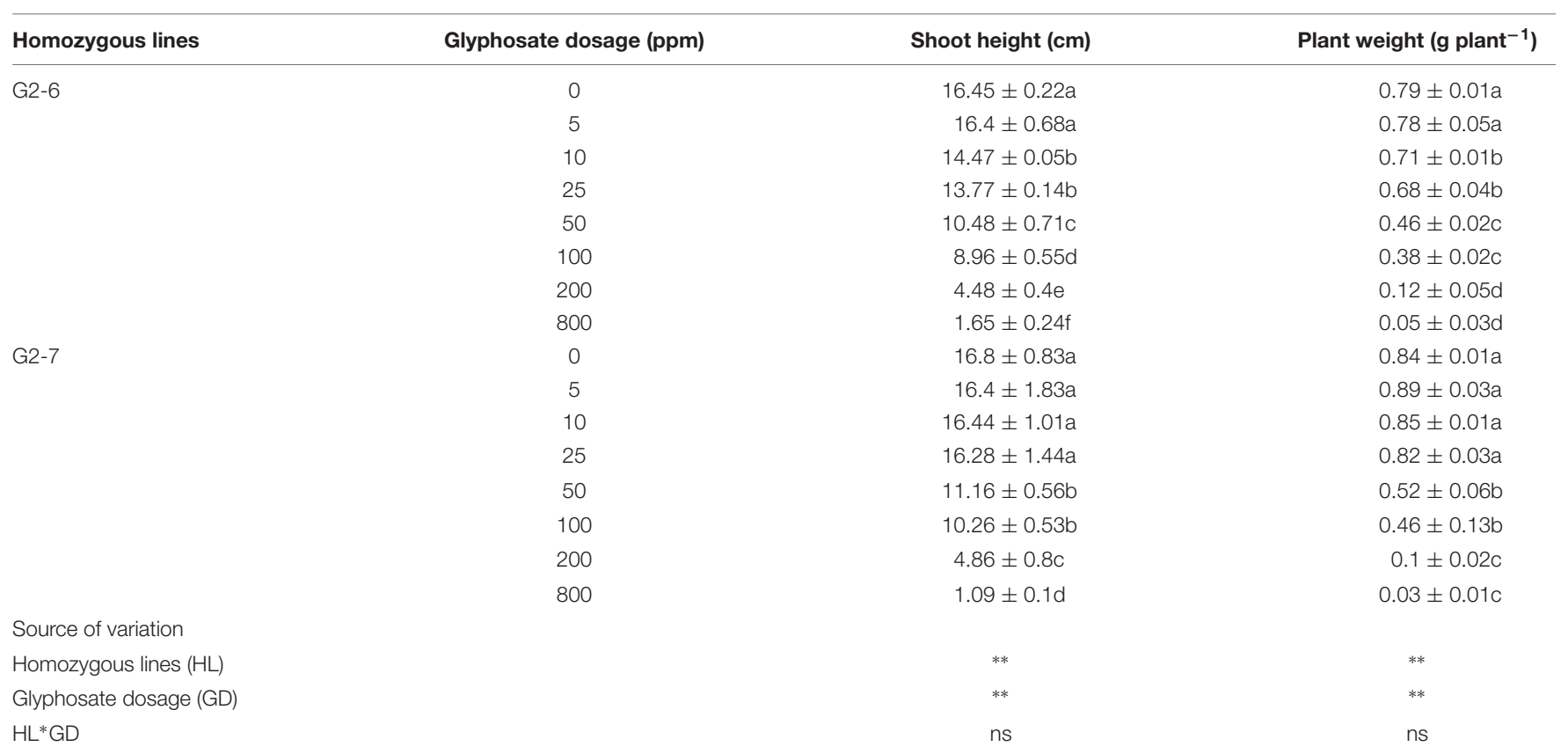

The parameters are shown as average values ( \pm standard deviation) that were collected from 40 plants in three replicates for each treatment. Numbers followed by different letters indicate significant differences $(P<0.05)$. ns, not significant $(P>0.05)$. ** Significant at $P<0.01$. 

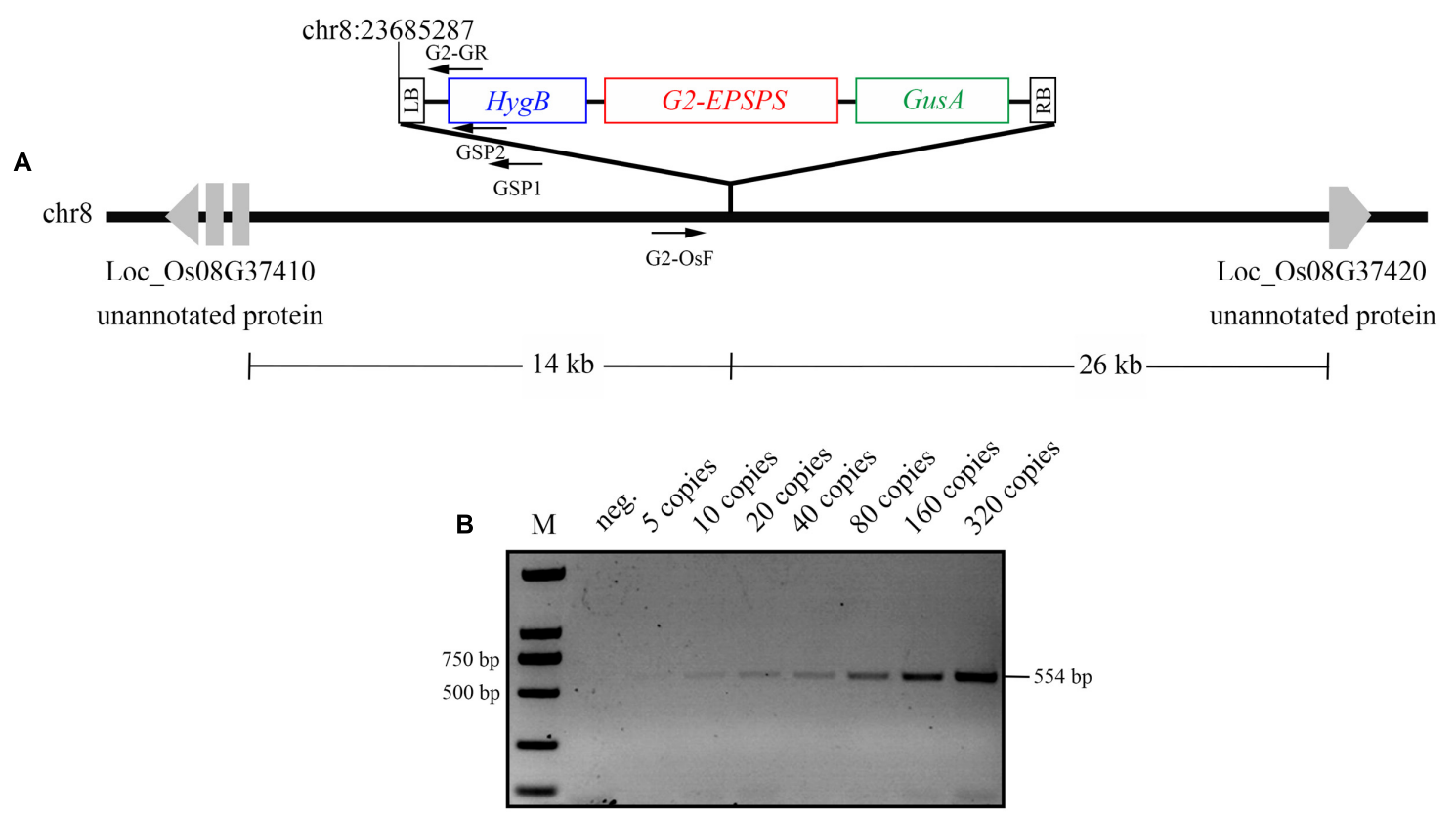

FIGURE 5 | Integration-site analysis and integration-event-specific PCR analysis. (A) The T-DNA LB integration site was identified by GenomeWalker PCR with specific primers GSP1, GSP2. The event-specific primers G2-OsF/G2-GR were designed according to the 5' -flanking sequence of the T-DNA of G2-6 transgenic rice and the left-border sequence of 13UG2. (B) Identification of the detection limit of transgenic plants by integration-event-specific PCR. Transgenic plant G2-6 template DNA copies were diluted to concentrations of 5, 10, 20, 40, 80, 160, and 320 copies as templates for integration-event-specific PCR.

to Zhu et al. (2013), the allergenic and toxicity analysis demonstrated that no amino acid sequence similarities were observed between G2-EPSPS enzymes and known allergenic and toxic proteins. The G2-EPSPS enzyme is readily degraded in simulated gastric/intestinal fluid within 15 s. In addition, a 90day feeding trial in Sprague-Dawley (SD) rats of G2-EPSPS GM maize indicated that GM glyphosate-tolerant maize was as safe and nutritious as conventional maize. Further, a 90-day feeding study of the stacked trait GM maize GH5112E-117C (obtained from Beijing Origin Seed Technology, Inc., China) with Cry $1 A h$ and G2-EPSPS gene was conducted by Han et al. (2016), and the results were similar to those of Zhu et al. (2013). These risk assessments of GM maize indicate that there is little potential risk to food safety through introducing the G2-EPSPS enzyme into food or feed (Zhu et al., 2013).

Research into rice tolerance to the herbicide glyphosate is mainly focused on the several established strains of glyphosatetolerant rice. Previous results show that all transgenic rice with the G6 gene survived under $8 \mathrm{~g} / \mathrm{L}, 100 \mathrm{ml} / \mathrm{m}^{2}$ glyphosate (Zhao et al., 2011); the resistance level of MdEPSPS mutant transgenic plants is up to $2.5 \%$ at $10 \mathrm{~L} /$ ha (Tian et al., 2013); and that Os-mEPSPS and ASAL genes are co-expressed in rice. The leaves of transgenic seedlings remain fully expanded and green after being grown for $24 \mathrm{~h}$ in $4 \mathrm{mM}$ glyphosate solution and subsequently transferred to a hydroponic solution without glyphosate (Chandrasekhar et al., 2014). Furthermore, CP4EPSPS transgenic rice can tolerate up to $1 \%$ of commercial Roundup, which is five times the dose used to kill weeds under field conditions (Chhapekar et al., 2015). The VvEPSPS mutant gene can tolerate up to $1 \mathrm{~L} /$ ha glyphosate (Tian et al., 2015), and $A r o A_{\text {J.sp }}$ allows transgenic rice to tolerate up to $3360 \mathrm{~g} / \mathrm{ha}$ glyphosate, a dosage that is fourfold the recommended agricultural application level (Yi et al., 2016). I. variabilis-EPSPS transgenic rice can sprout on a medium containing $2160 \mathrm{mg} \mathrm{L}^{-1}$ and G2-EPSPS candidate transgenic lines are not affected even when the glyphosate dosage increases to $8400 \mathrm{~g} \mathrm{ha}^{-1}$ (Cui et al., 2016). Since its isolation, the G2-EPSPS gene has been shown to confer good glyphosate resistance in many plants. The genetic glyphosate-tolerant rice containing the G2-EPSPS gene that we generated in the current study can tolerate a concentration of 20,000 ppm glyphosate [equivalent to 5\% (v/v) Roundup (isopropyl amine salt at $41 \% \mathrm{w} / \mathrm{v}$ ), $20 \mathrm{~g}^{-1}$ or $20 \mathrm{mM}$ ]; in contrast, 1000 ppm glyphosate was sufficient to kill non-transgenic rice and most weeds. The dosage we used in this report is about 20 -fold the recommended concentration. Furthermore, under hydroponic conditions, transgenic rice roots total immersion into the nutrient solution at different concentrations of glyphosate, through to the shoot length measurement and statistical analysis, the two transgenic lines improved the glyphosate resistance by about 100 -fold over $\mathrm{ZH} 11$. These results indicated that the G2EPSPS gene conferred a high tolerance to glyphosate herbicide in rice, and this is consistent with previous research results on other plants.

It is widely known that the T-DNA insertion may confer some unexpected traits on transgenic plants (Latham et al., 2006). The T-DNA insertional mutagenesis and the unexpected effect from the context gene may lead G2-6 and G2-7 to respond differently to glyphosate. In our research, both G2-6 and G2-7 
showed similar expression levels of the integrated G2-EPSPS gene, but there were small differences between G2-6 and G2-7; for example, hydroponic cultured G2-7 was significantly inhibited at 50 ppm glyphosate whereas G2-6 was significantly inhibited at $10 \mathrm{ppm}$, and the G2-7 transgenic line showed greater plant height when sprayed with $8000-20,000$ ppm glyphosate in the field. Even though these are small differences, they demonstrated a similar response trend to glyphosate pressure. For example, both G2-6 and G2-7 plant height were inhibited when sprayed with 3000 ppm and 5000 ppm glyphosate, and the inhibition was more significant when the glyphosate concentration was equal to or greater than $8000 \mathrm{ppm}$. However, plant height was not inhibited significantly when the glyphosate concentration was greater than $8000 \mathrm{ppm}$. Hydroponic culture using different concentrations of glyphosate showed that G2-6 and G2-7 plant height were both inhibited by $50 \%$ relative height at about $100 \mathrm{ppm}$ glyphosate, and the heights of both were completely inhibited at $800 \mathrm{ppm}$. Thus, the good glyphosate-tolerance presented in G2-6 and G2-7 is conferred by the G2-EPSPS gene and not by the specificity of individual transformation events.

Transferred genes must be both stably integrated and expressed, this stability is a prerequisite for commercial use (Mehrotra and Goyal, 2013). The establishment of the transformation-event-specific PCR detection method is important for transgenic breeding and the protection of food, feed, and environmental safety (Holst-Jensen et al., 2012; Lee et al., 2015; Guo et al., 2016). In the current study, an eventspecific PCR system for the transformation of transgenic rice G2-6 was established, and each generation of G2-6 transgenic rice was detected by event-specific PCR analysis. The results also showed that the position of the T-DNA remained unchanged, and provided a basis for the evaluation of G2-6 transgenic rice.

\section{REFERENCES}

Chandrasekhar, K., Reddy, G. M., Singh, J., Vani, K., Vijayalakshmi, M., Kaul, T., et al. (2014). Development of transgenic rice harbouring mutated rice 5enolpyruvylshikimate 3-phosphate synthase (Os-mEPSPS) and Allium sativum leaf agglutinin (ASAL) genes conferring tolerance to herbicides and sap-sucking insects. Plant Mol. Biol. Rep. 32, 1146-1157. doi: 10.1007/s11105-014-0715-3

Chhapekar, S., Raghavendrarao, S., Pavan, G., Ramakrishna, C., Singh, V. K., et al. (2015). Transgenic rice expressing a codon-modified synthetic $\mathrm{CP}_{4}$-EPSPS confers tolerance to broad-spectrum herbicide, glyphosate. Plant Cell Rep. 34, 721-731. doi: 10.1007/s00299-014-1732-2

Cui, Y., Huang, S., Liu, Z., Yi, S., Zhou, F., Chen, H., et al. (2016). Development of novel glyphosate-tolerant japonica rice lines: a step toward commercial release. Front. Plant Sci. 7:1218. doi: 10.3389/fpls.2016.01218

Duke, S. O., and Powles, S. B. (2008). Glyphosate: a once-in-a-century herbicide. Pest Manag. Sci. 64, 319-325. doi: 10.1002/ps.1518

Dun, B., Wang, X., Lu, W., Zhao, Z., Hou, S., Zhang, B., et al. (2007). Reconstitution of glyphosate resistance from a split 5-enolpyruvyl shikimate-3-phosphate synthase gene in Eschetichia coli and transgenic tobacco. Appl. Environ. Microbiol. 73,7997-8000. doi: 10.1128/AEM.00956-07

Farooq, M., Siddique, K. H. M., Rehman, H., Aziz, T., Lee, D., and Wahid, A. (2011). Rice direct seeding: experiences, challenges and opportunities. Soil Till. Res. 111, 87-98.

Goldsbrough, P. B., Hatch, E. M., Huang, B., Kosinski, W. G., Dyer, W. E., Herrmann, K. M., et al. (1990). Gene amplification in glyphosate tolerant tobacco cells. Plant Sci. 72, 53-62. doi: 10.1016/0168-9452(90)90186-R

\section{CONCLUSION}

The G2-EPSPS gene shows promising potential for commercial application in the improvement of glyphosate-resistant rice.

\section{AUTHOR CONTRIBUTIONS}

ZW and XW conceived and designed the experiments, YD performed the experiments, and wrote the paper, XJ constructed the plant transformation vector and performed the rice transformation, QT and JC improved the language, YD, QT, XinZ, XiaZ, JY, XL analyzed the data.

\section{FUNDING}

This study was supported by the Major Project of China on New Varieties of GMO Cultivation (Grant No. 2016ZX08010003), the Special Fund for Agro-scientific Research in the Public Interest of the People's Republic of China (Grant No. 201403075), and National Natural Science Foundation of China (31100408).

\section{SUPPLEMENTARY MATERIAL}

The Supplementary Material for this article can be found online at: http://journal.frontiersin.org/article/10.3389/fpls.2017.00885/ full\#supplementary-material

FIGURE S1 | G2-EPSPS gene expression level in T3 transgenic lines.

FIGURE S2 | Integration-event-specific PCR of G2-6 transgenic lines.

Guo, B., Guo, Y., Hong, H., Jin, L., Zhang, L., Chang, R. Z., et al. (2015). Coexpression of G2-EPSPS and glyphosate acetyltransferase GAT genes conferring high tolerance to glyphosate in soybean. Front. Plant Sci. 6:847. doi: 10.3389/ fpls.2015.00847

Guo, B., Guo, Y., Hong, H., and Qiu, L. J. (2016). Identification of genomic insertion and flanking sequence of G2-EPSPS and GAT transgenes in soybean using whole genome sequencing method. Front. Plant Sci. 7:1009. doi: 10.3389/ fpls.2016.01009

Han, S., Zou, S., He, X., Huang, K., and Mei, X. (2016). Potential subchronic food safety of the stacked trait transgenic maize GH5112E-117C in Sprague-Dawley rats. Transgenic Res. 25, 453-463. doi: 10.1007/s11248-0169944-6

Hiei, Y., Ohta, S., Komari, T., and Kumashiro, T. (1994). Efficient transformation of rice (Oryza sativa L.) mediated by Agrobacterium and sequence analysis of the boundaries of the T-DNA. Plant J. 6, 271-282. doi: 10.1046/j.1365-313X. 1994.6020271.x

Holst-Jensen, A., Bertheau, Y., de Loose, M., Grohmann, L., Hamels, S., Hougs, L., et al. (2012). Detecting un-authorized genetically modified organisms (GMOs) and derived materials. Biotechnol. Adv. 30, 1318-1335 doi: 10.1016/j. biotechadv.2012.01.024

Lee, D. H., Choi, S. L., Rha, E., Kim, S. J., Yeom, S. J., Moon, J. H., et al. (2015). A novel psychrophilic alkaline phosphatase from the metagenome of tidal flat sediments. BMC Biotechnol. 15:1. doi: 10.1186/s12896-015-0115-2

Latham, J. R., Wilson, A. K., and Steinbrecher, R. A. (2006). The mutational consequences of plant transformation. J. Biomed. Biotechnol. 2006:25376. doi: $10.1155 / J B B / 2006 / 25376$ 
Liu, Y., Zhang, Y., Liu, Y., Lu, W., and Wang, G. (2015). Metabolic effects of glyphosate on transgenic maize expressing a G2-EPSPS gene from Pseudomonas fluorescens. J. Plant Biochem. Biotechnol. 24, 233-241. doi: 10.1007/s13562-0140263-9

Mehrotra, S., and Goyal, V. (2013). Evaluation of designer crops for biosafety - a scientist's perspective. Gene 515, 241-248. doi: 10.1016/j.gene2012.12.029

Nguyen, N. V., and Ferrero, A. (2006). Meeting the challenges of global rice production. Paddy Water Environ. 4, 1-9. doi: 10.1007/s10333-005 $-0031-5$

Porebski, S., Bailey, L. G., and Baum, B. R. (1997). Modification of a CTAB DNA extraction protocol for plants containing high polysaccharide and polyphenol components. Plant Mol. Biol. Rep. 15, 8-15.

Ray, D. K., Mueller, N. D., West, P. C., and Foley, J. A. (2013). Yield trends are insufficient to double global crop production by 2050. PLOS ONE 8:e66428. doi: 10.1371/journal.pone.0066428

Seefeldt, S. S., Jensen, J. E., and Fuerst, E. P. (1995). Log-logistic analysis of herbicide dose-response relationships. Weed Technol. 9, 218-227.

Shah, D. M., Horsch, R. B., Klee, H. J., Kishore, G. M., Winter, J. A., Tumer, N. E., et al. (1986). Engineering herbicide tolerance in transgenic plants. Science 233, 478-481. doi: 10.1126/science.233.4762.478

Singh, V., Jat, M. L., Ganie, Z. A., Chauhan, B. S., and Gupta, R. K. (2016). Herbicide options for effective weed management in dry direct-seeded rice under scented rice-wheat rotation of western Indo-Gangetic Plains. Crop Prot. 81, 168-176. doi: 10.1016/j.cropro.2015.12.021

Stalker, D. M., Hiatt, W. R., and Comai, L. (1985). A single amino acid substitution in the enzyme 5-enolpyruvylshikimate-3-phosphate synthase confers resistance to the herbicide glyphosate. J. Biol. Chem. 260, 4724-4728.

Tian, Y., Xu, J., Peng, R., Xiong, A., Xu, H., Zhao, W., et al. (2013). Mutation by DNA shuffling of 5-enolpyruvylshikimate-3-phosphate synthase from Malus domestica for improved glyphosate resistance. Plant Biotechnol. J. 11, 829-838. doi: $10.1111 /$ pbi.12074

Tian, Y., Xu, J., Xing, X., Zhao, W., Fu, X., Peng, R., et al. (2015). Improved glyphosate resistance of 5-enolpyruvylshikimate-3-phosphate synthase from Vitis vinifera in transgenic Arabidopsis and rice by DNA shuffling. Mol. Breed. 35:148. doi: 10.1007/s11032-0150327-0

Williams, G. M., Kroes, R., and Munro, I. C. (2000). Safety evaluation and risk assessment of the herbicide Roundup and its active ingredient, glyphosate, for humans. Regul. Toxicol. Pharmacol. 31, 117-165. doi: 10.1006/rtph.1999.1371

Yi, S., Cui, Y., Zhao, Y., Liu, Z., Lin, Y., and Zhou, F. (2016). A novel naturally occurring Class I 5-Enolpyruvylshikimate-3-Phosphate synthase from Janibacter sp. confers high glyphosate tolerance to rice. Sci. Rep. 6:19104. doi: $10.1038 /$ srep19104

Zhang, X., Tang, Q., Wang, X., and Wang, Z. (2016). Structure of exogenous gene integration and event-specific detection in the glyphosate-tolerant transgenic cotton line BG2-7. PLoS ONE 11: e0158384. doi: 10.1371/journal.pone.0158384

Zhao, T., Lin, C., and Shen, Z. (2011). Development of transgenic glyphosateresistant rice with G6 gene encoding 5-enolpyruvylshikimate-3-phosphate synthase. J. Integr. Agric. 10, 1307-1312. doi: 10.1016/S1671-2927(11)60123-5

Zhu, Y., He, X., Luo, Y., Zou, S., Zhou, X., Huang, K., et al. (2013). A 90-day feeding study of glyphosate-tolerant maize with the G2-aroA gene in Sprague-Dawley rats. Food Chem. Toxicol. 51, 280-287. doi: 10.1016/j.fct.2012.09.008

Zhu, Y., Yu, Z. L., and Lin, M. (2003). Bioresistance or biodegradation of glyphosate and construction of transgenic plants. Mol. Plant Breed. 4. 435-441.

Conflict of Interest Statement: The authors declare that the research was conducted in the absence of any commercial or financial relationships that could be construed as a potential conflict of interest.

Copyright (c) 2017 Dong, Jin, Tang, Zhang, Yang, Liu, Cai, Zhang, Wang and Wang. This is an open-access article distributed under the terms of the Creative Commons Attribution License (CC BY). The use, distribution or reproduction in other forums is permitted, provided the original author(s) or licensor are credited and that the original publication in this journal is cited, in accordance with accepted academic practice. No use, distribution or reproduction is permitted which does not comply with these terms. 